\title{
Circularly Polarized Microstrip Antennas with Proximity Coupled Feed for Circularly Polarized Synthetic Aperture Radar
}

\author{
Merna Baharuddin ${ }^{1}$ and Josaphat Tetuko Sri Sumantyo ${ }^{2}$ \\ ${ }^{1}$ Department of Electrical Engineering, Faculty of Engineering, Hasanuddin University \\ Jl. Perintis Kemerdekaan, Kampus Tamalanrea \\ Makassar 90211, \\ ${ }^{2}$ Center for Environmental Remote Sensing, Chiba University \\ 1-33, Yayoi, Inage, Chiba 263-8522 \\ Indonesia \\ 2Japan
}

\section{Introduction}

Synthetic aperture radar (SAR) is an active sensor that can produce high resolution imagery in microwave bands.

A circularly polarized SAR (CP-SAR) to be launched onboard a micro-satellite is currently developed in the Microwave Remote Sensing Laboratory (MRSL) of the Center for Environmental Remote Sensing (CEReS), Chiba University. As part of the project, an airborne CP-SAR development is also undertaken in order to obtain sufficient knowledge of CP-SAR sensor systems. An L-band CP-SAR system will be designed for operation onboard an unmanned aerial vehicle (UAV).

Conventional SAR systems have been based on linearly polarized (LP) antenna systems (Nemoto et al. 1991, Raney et al. 1991). However, there are limitations due to the propagation phenomena. Especially for space propagation, electromagnetic waves propagating through the ionosphere interact with electrons and magnetic fields. As a result, the polarization vector of the electric field is rotated by the Faraday rotation effect (Rignot, 2000).

The destructive effects mentioned above of a SAR sensor with linear polarization can be solved by the use of CP-SAR. In addition, it has been pointed out (Raney, 2007) that a full characterization of SAR signals backscattered from a random object can only be possible through the use of circular polarization. Hence, compared to a linear SAR sensor, a greater amount of information about scenes and targets being imaged would be provided with a CP-SAR sensor. The operational frequency is chosen to be $1.27 \mathrm{GHz}$ in L-band considering its superior features on particular applications.

As the Microwave Remote Sensing Laboratory, Center for Environmental Technology, Chiba University is developing a CP-SAR sensor onboard an UAV, an antenna for the Lband CP-SAR sensor is required. 
Until now, a number of airborne SAR has been developed with LP antennas installed in the SAR sensor onboard. The E-SAR (Horn, 1996), implementing pyramidal horn for its X-band antenna, microstrip patch arrays for its C- and P-band antenna, and passive microstrip phased arrays (L- and S-band). A waveguide phased array antenna is implemented in the Cband airborne Danish SAR system (Madsen et al., 1991). The UAVSAR, a polarimetric UAV SAR system developed by NASA's Jet Propulsion Laboratory implementing a phased array antenna consists of LP microstrip elements.

Therefore, to investigate the new SAR sensor with $\mathrm{CP}$ antennas, in this chapter, $\mathrm{CP}$ microstrip elements are proposed and developed to be implemented in an array antenna for the CP-SAR sensor onboard an UAV. The numerical simulations and the measurement results are shown and discussed.

The remainder of this chapter is organized as follows. Section 2 explains the methodology used to design and develop the $\mathrm{CP}$ microstrip antennas. The numerical simulation and measurement results for the single elements are presented in section 3 along with explanations of the results, whereas for the array antenna is discussed in section 4 . Finally, the summary and conclusions of this work are presented in the section 5 .

\section{Microstrip antennas development methodology}

\subsection{Specification of the antenna}

Specification of the CP-SAR onboard UAV is shown in Table 1.

\begin{tabular}{ll}
\hline \hline Parameter & Specification \\
\hline Frequency $f$ & $1.27 \mathrm{GHz}(\mathrm{L}$ band $)$ \\
\hline Chirp bandwidth $\Delta f$ & $10 \mathrm{MHz}$ \\
\hline Polarization & Transmitter $:$ RHCP \\
\hline \multicolumn{2}{l}{ Receiver $:$ RHCP + LHCP } \\
\hline Gain $G$ & $>20 \mathrm{dBic}$ \\
\hline Axial ratio AR & $<3 \mathrm{~dB}($ main beam $)$ \\
\hline Antenna size & $2 \mathrm{~m}($ azimuth $) \times 0.7 \mathrm{~m}$ (range) \\
\hline Beam width & $8^{\circ}($ azimuth $) \times 25^{\circ}$ (range $)$ \\
\hline Resolution & $\approx 1.4 \mathrm{~m}($ azimuth $) \times 15 \mathrm{~m}$ (range) \\
\hline Altitude range & $1-4 \mathrm{~km}$ \\
\hline \hline
\end{tabular}

Table 1. Specification of CP-SAR Onboard Unmanned Aerial Vehicle.

An array of microstrip antenna elements will be designed to meet the specification listed in the Table 1.

The requirements for the range resolution $(15 \mathrm{~m})$ determine the antenna bandwidth of 10 $\mathrm{MHz}$, or less than $1 \%$ of the operation frequency of $1.27 \mathrm{GHz}$.

$$
\delta_{R}=\frac{c}{2 B},
$$

where

$\delta_{\mathrm{R}}=$ range resolution $(\mathrm{m})$

$\mathrm{c}=$ speed of light $(\mathrm{m} / \mathrm{sec})$ 
$\mathrm{B}=$ bandwidth $(\mathrm{Hz})$

This bandwidth requirement must be compatible with a low axial ratio (AR) (below $3 \mathrm{~dB}$ ) for ensuring transmitting/receiving circularly polarized waves. To satisfy the matching of input impedance, the return loss must be smaller than $10 \mathrm{~dB}$ in this bandwidth range.

The primary considerations in the design and subsequent fabrication processes are low cost, light weight and ease of manufacturing. One antenna aperture will be used for both transmitting and receiving CP-SAR signals, with a circulator to control the direction of signal flow into/out from the CP-SAR sensor circuit (Chan, 2004). The CP-SAR antenna consists of an array of single antenna elements, each being a microstrip antenna for circular polarization. Even though it is also possible to obtain a CP array comprising of linearlypolarized elements, the electrical performance of a CP-elements array is generally better than that of an LP-elements array (Bhattacharyya, 2008) : namely, (1) bandwidth of a CPelements array is significantly wider (about twice) than that of LP-elements array; and (2) gain of a CP-elements array is significantly higher than that of LP-elements array for large element spacing. The single element patches which have been optimized are then spatially arranged to form a planar array. A better control of the beam shape and position in space can be achieved by correctly arranging the elements along a rectangular grid to form a planar array. The beam pattern for optimum ground mapping function is cosecant-squared beam in the elevation plane (E-plane) which can correct the range gain variation and pencil beam in the azimuth plane (H-plane) (Vetharatnam et al., 2006). The antenna side lobe levels in the azimuth plane must be suppressed in order to avoid the azimuth ambiguity. To deal with reflection, the antenna side lobes and back lobes also must be suppressed. The antenna gain is mostly determined by the aperture size and inter-element separation.

Feed network is implemented in a separate substrate as the feeding method is proximity coupled. The feeding array is parallel to the antenna array, corresponding to the scheme of proximity-coupled, corporate feeding. This type of feed method allows better optimization of both feeding and antenna array structures individually. Concept of the feed network layout proposed here is the $\mathrm{n} \times \mathrm{n}$ microstrip arrays with a power dividing network, consisting of an element building block of $2 \times 2$ " $\mathrm{H}$ " shaped feed network (Levine et al., 1989). Constructions of a larger array can be achieved by combining the " $\mathrm{H}$ " networks.

In addition to the entire system specification, a list of specification for the single element microstrip antenna is also need to be given. The specification is shown in Table 2.

\begin{tabular}{ll}
\hline \hline Parameter & Specification \\
\hline Frequency $f$ & $1.27 \mathrm{GHz}$ (L band) \\
\hline Chirp bandwidth $\Delta f$ & $10 \mathrm{MHz}$ \\
\hline Polarization & Transmitter : RHCP \\
\hline & Receiver : RHCP + LHCP \\
\hline Gain $G$ & $>5 \mathrm{dBic}$ \\
\hline Axial ratio AR & $<3 \mathrm{~dB}$ (main beam) \\
\hline$S_{11}$ & $<-10 \mathrm{~dB}$ \\
\hline \hline
\end{tabular}

Table 2. Specification of single-element microstrip antenna for CP-SAR Onboard Unmanned Aerial Vehicle. 


\subsection{Design procedure}

\subsubsection{Design and analysis tools: IE3D}

A full-wave analysis tool (IE3D Zeland software) based on the Method of Moment (MoM) algorithm is used for design and analyzing by electromagnetically simulate the antenna models. IE3D is an integrated full-wave electromagnetic simulation and optimization package, which is capable of generating high accuracy analysis and design of microwave electronics component including antennas both 3D and planar (Zeland Software Inc., 2006). Results obtained from the IE3D simulation are the $S$ parameter, input impedance, radiation pattern, and current distribution.

\subsubsection{Developed antennas}

The developed antennas comprise of four types of microstrip antennas and one array configuration. The first model investigated and developed with findings of Axial Ratio disturbance from the presence of holes for installing plastic screws. The other three models are new developed configuration of elliptical microstrip antennas. The array configuration is proposed from the elliptical microstrip antenna. The list of the developed antennas is as follows:

1. Equilateral Triangular Microstrip Antenna

2. Elliptical Microstrip Antenna

3. Elliptical Annular Ring Microstrip Antenna

4. Elliptical Annular Ring Microstrip Antenna Having a Sine Wave Periphery An array of the elliptical microstrip element is developed and simulated.

\subsection{Prototype fabrication}

The equilateral triangular microstrip antenna, elliptical microstrip antenna, elliptical annular ring microstrip antenna, and the elliptical annular ring microstrip antenna having a sine wave periphery models have been fabricated to verify the simulation results. Careful and precise fabrication process is required to produce radiating behavior similar to the simulated model. The stages for fabrication is as follows: (1) Microwave Artwork;(2) Etching;(3) Bonding.

After installing the plastic screws, then the antenna is ready for measurement. Pictures of fabricated antennas are shown in Figure 1.

\subsection{Measurement}

The reflection coefficient and input impedance were measured with the RF Vector Network Analyzer (Agilent, E5062A, ENA-L). Before performing this measurement, a standard calibration process is needed to minimize imperfections which will cause the equipment to yield less than ideal measurements. There are three calibrated reflection standards: a short circuit, an open circuit, and a matched load. This one-port calibration makes it possible to derive the actual reflection S-parameters of the Antenna-under-test (AUT).

The antenna gain, AR, and radiation patterns were measured inside the anechoic chamber of MRSL, having a dimension of $4 \times 8.5 \times 2.4 \mathrm{~m}^{3}$. The measurement system is schematically shown in Figure 2 (Wissan et al., 2009). The AR vs. frequency characteristic, AR pattern, gain vs. frequency characteristic and gain pattern were measured using conical log-spiral LHCP/RHCP antennas and a dipole antenna as the standard reference. Precise alignment between AUT and the conical log-spiral antenna is indispensable for obtaining accurate measurement results. 


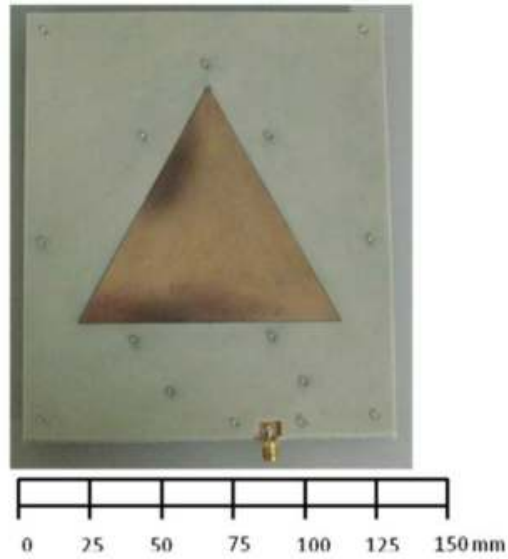

(a)

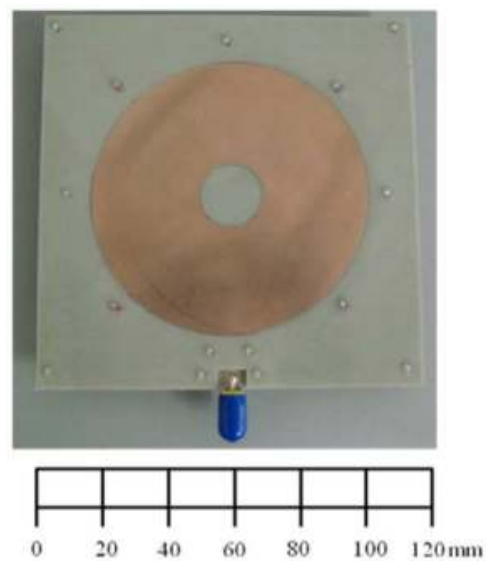

(c)

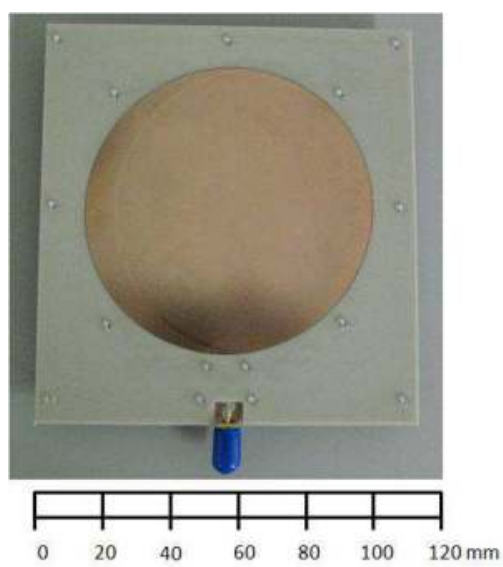

(b)
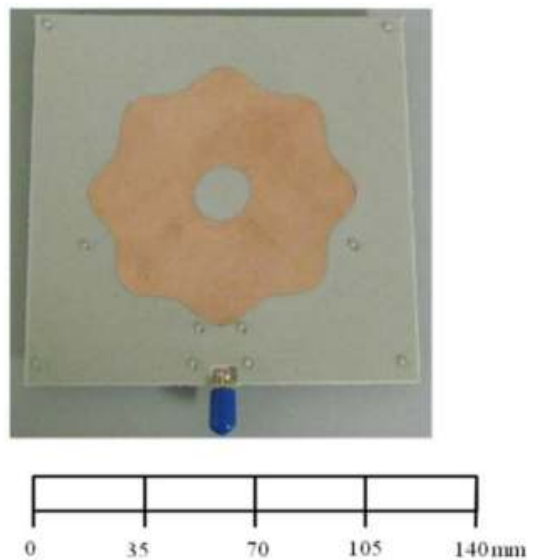

(d)

Fig. 1. Fabricated microstrip antennas ; (a) equilateral triangular microstrip antenna, (b) elliptical microstrip antenna, (c) elliptical annular ring microstrip antenna, and (d) elliptical annular ring microstrip antenna having a sine wave periphery. 


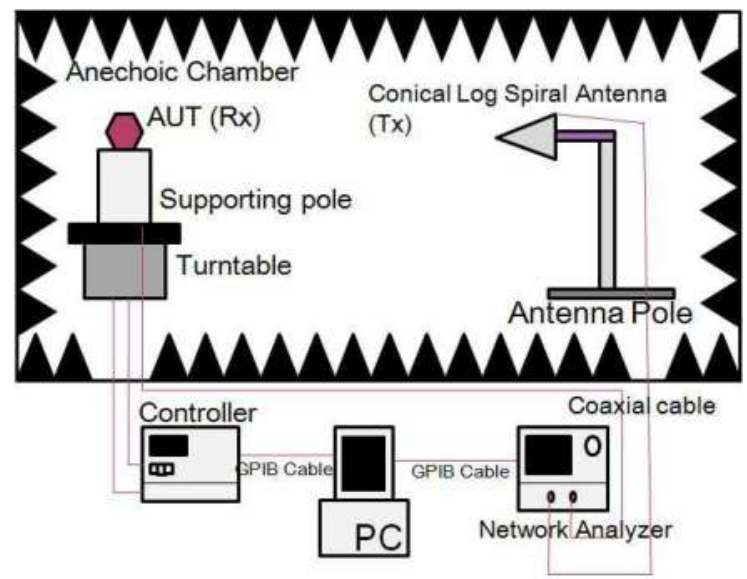

(a)

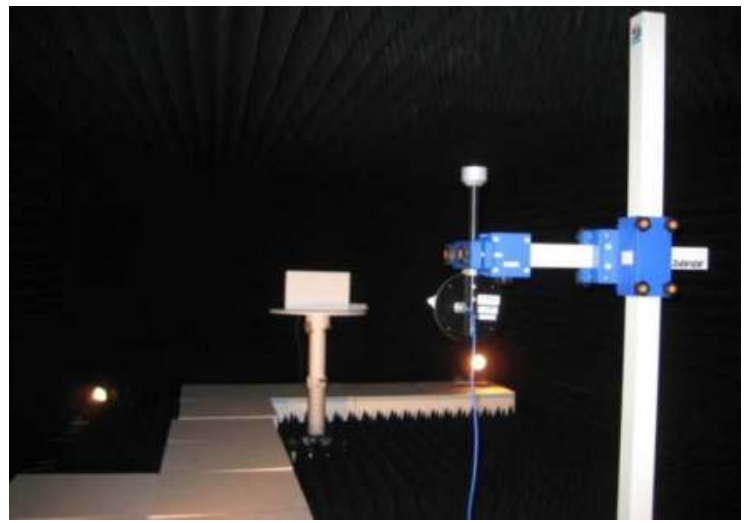

(b)

Fig. 2. (a) Schematic of the measurement system; (b) Anechoic chamber at MRSL, Chiba University.

\section{Results and discussion on the simulation and measurement of the microstrip antenna elements}

\subsection{Equilateral triangular microstrip antenna}

Previously, a number of CP triangular microstrip antennas have been developed, some of them are reported by Garg et al. (2001), Suzuki et al. (2007), and Karimabadi et al. (2008). However, almost all the developed models implement single-feed type with coaxial probe feeding method, which possess some problems, namely : (1) the CP radiator (patch) from single feed type antenna will generate an unstable current distribution which will impair the performance of axial ratio in array configuration; (2) single feed type antenna is not preferred type for a multi polarization (RHCP and LHCP) array due to the poorer isolation parameter compared to the dual feed type one (3) probe feed implementation is more 
complex in fabrication process for a $\mathrm{CP}$ antenna. A dual feed equilateral triangular microstrip element antenna has superior properties and would be a good element for the CP-SAR implementation.

The configuration of the radiating element together with the microstrip line feed and ground plane is shown in Figure 3(a), where important parameters are labeled. Side view is depicted in Figure $3(\mathrm{~b})$. The equilateral triangular radiator will generate a left-handed circular polarization (LHCP) by employing the dual feed method as shown in Figure 3(a). In order to generate a $90^{\circ}$ phase delay on one of the two modes, the line feed on the left side is approximately $\lambda / 4$ longer than the other.

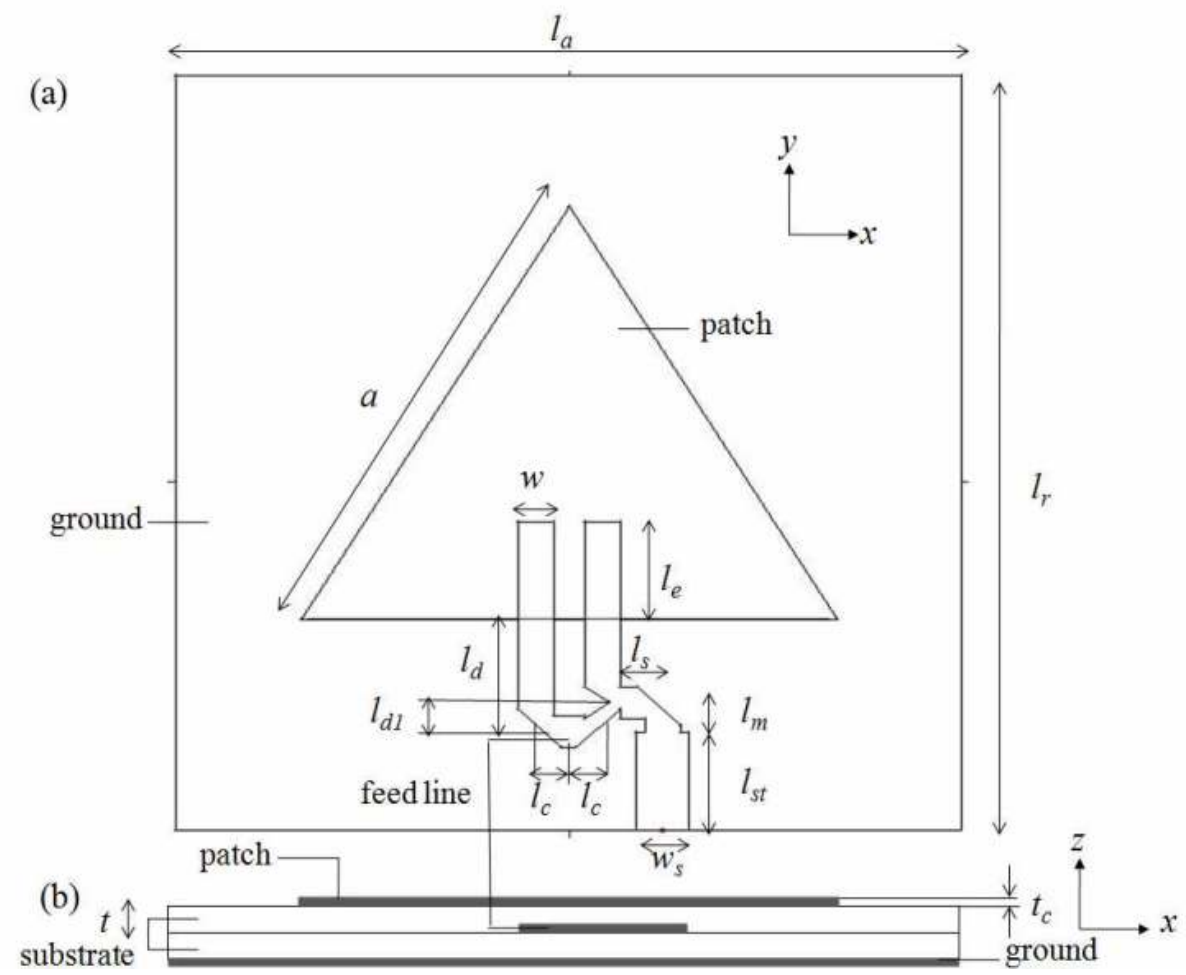

Fig. 3. Configuration of equilateral triangular patch antenna with proximity coupled feed; (a) top view and (b) side view.

Simulations with a finite-ground-plane model have been undertaken to optimize the size parameters using a full-wave analysis tool (IE3D Zeland software) based on the method of moment (MoM) algorithm. The dimensions of the radiator, microstrip feed line and the ground plane for the equilateral triangular patch are tabulated in Table 3 in units of $\mathrm{mm}$. The geometry model is implemented on two substrates, each with thickness $t=1.6 \mathrm{~mm}$, with the conductor thickness $t_{\mathrm{c}} \approx 0.035 \mathrm{~mm}$, relative permittivity $\varepsilon_{\mathrm{r}}=2.17$ and loss $\tan \delta$ (dissipation factor) 0.0005 . 


\begin{tabular}{cc}
\hline \hline Parameter & Dimension \\
\hline$a$ & 102.75 \\
\hline$w$ & 6.8 \\
\hline$l_{d}$ & 21.5 \\
\hline$l_{e}$ & 27 \\
\hline$l_{d 1}$ & 6.9 \\
\hline$l_{c}$ & 9.2 \\
\hline$l_{s}$ & 10.1 \\
\hline$l_{m}$ & 3.9 \\
\hline$l_{s t}$ & 21.5 \\
\hline$w_{s}$ & 10.2 \\
\hline$l_{a}$ & 146.1 \\
\hline$l_{r}$ & 163.1 \\
\hline \hline
\end{tabular}

Table 3. Geometry parameters (in units of $\mathrm{mm}$ ) of the equilateral triangular patch antenna.

\subsubsection{Parameter study}

Parameter study on the parameter $l_{c}$ (distance between the two feeds) was conducted since during the optimization process of the microstrip line feed configuration, it was observed that this parameter exerts a strong influence on both the $\mathrm{CP}$ frequency and the AR of the antenna. Figure 4 shows the result of the simulation, in which the frequency dependence of the AR is plotted for various values of the parameter $l_{c}$ while keeping the other parameters unchanged. Thus, the distance must be exact in order to achieve the orthogonality of the two modes fed from the current source to the triangular patch.

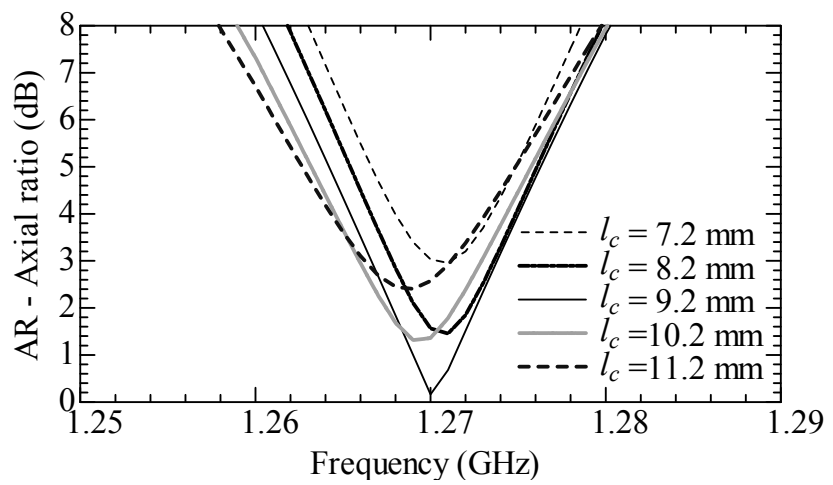

Fig. 4. Simulation results showing the frequency dependence of the axial ratio (AR) of the equilateral triangular microstrip antenna for various values of $l_{c}$.

\subsubsection{Simulation and measurement results and discussions}

The antenna efficiency from the simulation is $86.59 \%$. Simulated input impedance bandwidth is $26.0 \mathrm{MHz}$ whereas the measured one is $21.5 \mathrm{MHz}$ (Figure 5).

Figure 6 shows the gain simulated and measured at $\theta=0 \mathrm{o}$. While the gain of the antenna has been simulated to be $7.04 \mathrm{dBic}$ at $1.27 \mathrm{GHz}$, experimental results shows a smaller value by 
about $0.6 \mathrm{~dB}$. This difference may be ascribed to the fabrication imperfections (such as inaccuracy in the milling and etching processes and connector soldering) and the substrate loss.

Figure 6 also shows the simulated and measured results of AR. From this figure it can be seen that the 3-dB AR bandwidth from the simulation is $7.2 \mathrm{MHz}$ and from the measurement is $7.4 \mathrm{MHz}$ (ranging from $1.2653 \mathrm{GHz}$ to $1.2727 \mathrm{GHz}$ ). Even though the measurement result of $3-\mathrm{dB}$ AR bandwidth is slightly better than that of the simulation result, this bandwidth is still narrower than the target specification (10 MHz). To improve this situation, the next work will consider the technique to extend the 3-dB AR bandwidth.

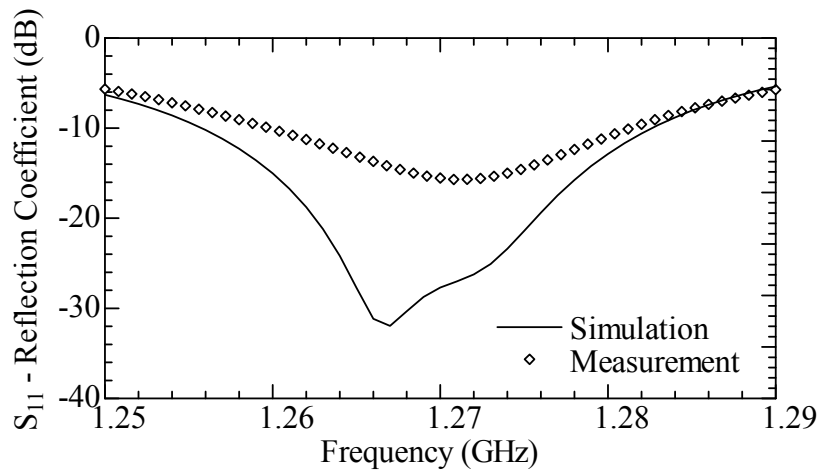

Fig. 5. Simulated and measured reflection coefficient

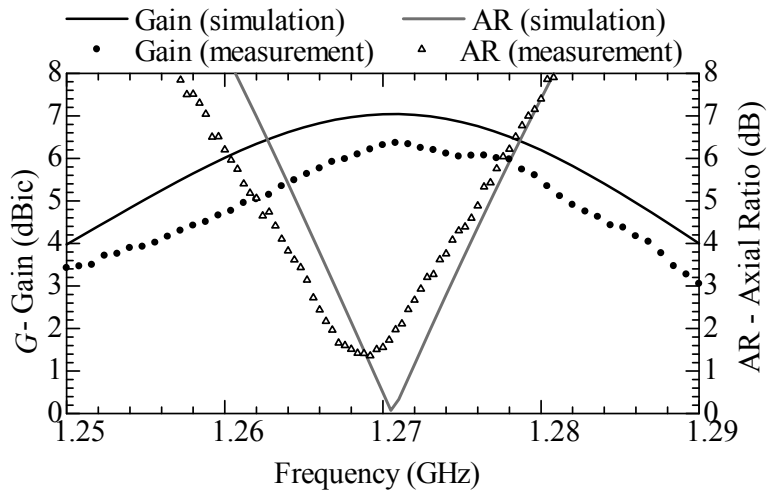

Fig. 6. Simulated and measured gain and $\mathrm{AR}$ at $\theta=0$.

Figures $7-10$ show the radiation pattern in terms of gain and $\mathrm{AR}$ at an azimuth angle $\mathrm{Az}=$ $0^{\circ}$ (and 180, $\mathrm{x}-\mathrm{z}$ plane) and $90^{\circ}$ (and 270, $\mathrm{y}-\mathrm{z}$ ) plane and at the frequency of $f=1.27 \mathrm{GHz}$. In Figure 7, a difference of around $0.7 \mathrm{~dB}$ is seen between the simulated model and the measured antenna on the gain radiation pattern. Figure 8 shows that the most beam radiated in the direction of $A z=0^{\circ}(x>0$ in Figure 8). Figure 9 shows the 90。 azimuth measurement of gain pattern. 


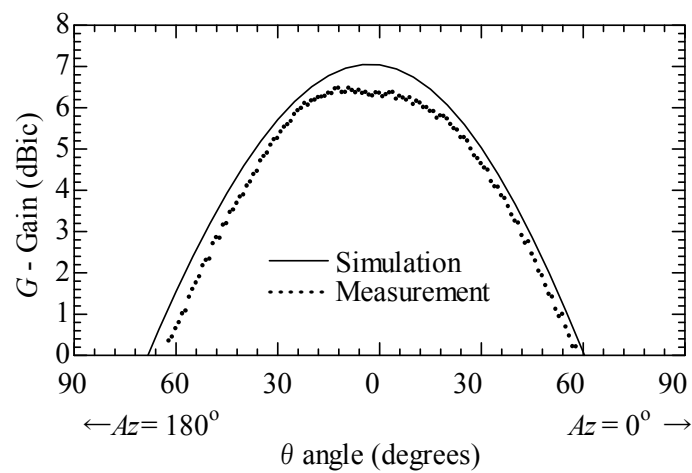

Fig. 7. Gain vs. theta angle (radiation pattern) in the theta plane $\left(\mathrm{Az}=0^{\circ}\right.$ and $\left.180^{\circ}\right)(x-z$ plane) at $f=1.27 \mathrm{GHz}$.

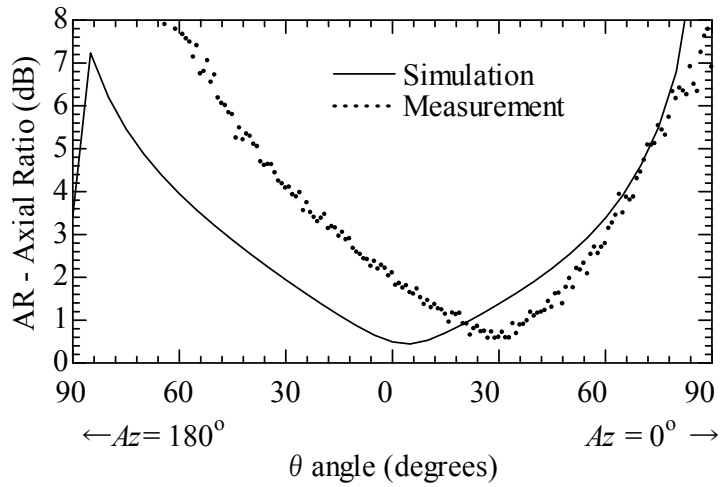

Fig. 8. Axial Ratio vs. theta angle (radiation pattern) in the theta plane $\left(\mathrm{Az}=0^{\circ}\right.$ and $\left.180^{\circ}\right)(x-$ $\mathrm{z}$ plane) at $f=1.27 \mathrm{GHz}$.

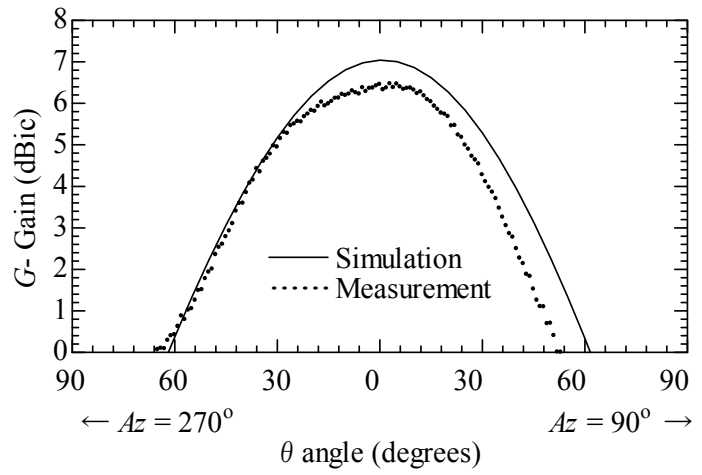

Fig. 9. Gain vs. theta angle (radiation pattern) in the theta plane $\left(\mathrm{Az}=90^{\circ}\right.$ and $\left.270^{\circ}\right)(\mathrm{y}-\mathrm{z}$ plane) at $f=1.27 \mathrm{GHz}$. 


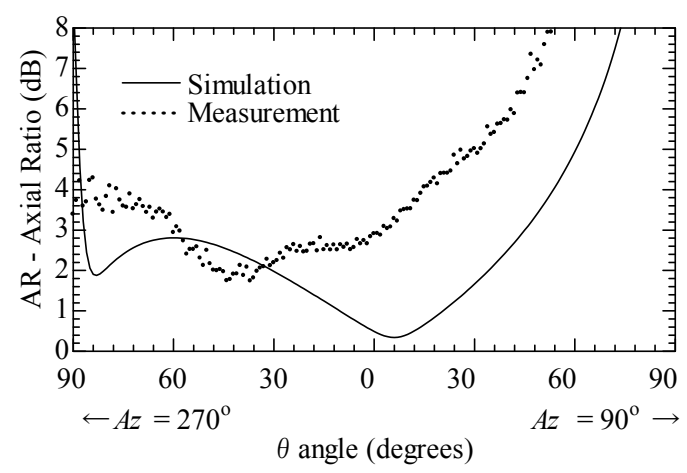

Fig. 10. Axial Ratio vs. theta angle (radiation pattern) in the theta plane $\left(\mathrm{Az}=90^{\circ}\right.$ and $\left.270^{\circ}\right)$ (y - z plane) at $f=1.27 \mathrm{GHz}$.

Most of the beam that has good $\mathrm{CP}$ characteristics is radiated in the direction of $\mathrm{Az}=270^{\circ}$ ( $y>0$ in Figure 10). There are some differences between the simulated and measured pattern of the antenna. This may be due to the slightly altered fabricated model and different measurement environment compared to the simulated model in the IE3D simulation environment. Especially the AR vs. angle results which show a larger difference compared with the gain one. The high sensitivity of AR behaviour to the measurement condition, the infinite lateral substrate extension in IE3D, and a possible of additional radiation from the edges of the substrate in the fabricated model may contribute to the differences.

\subsection{Elliptical microstrip antenna}

The requirement of a patch element for generating a circularly polarized radiation is that the patch must have orthogonal (in-phase and quadrature) fields of equal amplitude. Slightly elliptical patch can have a circular polarization radiation with a single feeding (Bailey et al. 1985, Shen 1981). In addition, an elliptical antenna element generally has an elliptically polarized radiation, but it has left-handed (or right-handed) circularly polarized (LHCP/RHCP) radiation when the feed point of the antenna element is located on the radial line rotated $45^{\circ}$ counterclockwise (or clockwise) to the semi major-axis of the ellipse (Bailey et al., 1985). Also according to Bailey et al. (1985), the best circular polarization radiation may be achieved by limiting the eccentricity of the ellipse to a range of 10 to $20 \%$.

The configuration of the radiating element together with the microstrip line feed and ground plane is shown in Figure 11(a), where important parameters are labeled. Although prior elliptical patch were based on the probe-feed method (Bailey et al. 1985, Shen 1981), in this chapter we adopt the proximity-coupled feeding method (Pozar et al., 1987). This approach has the advantage of easier adjustment in the process of design and fabrication processes, especially in producing good circular polarization with good impedance matching. Also, bandwidth enhancement and reduced parasitic radiation of the feeding network is achieved compared with other direct feeding methods.

The dimensions of the radiator, and the ground plane for the elliptical patch are $a=45.9$ $\mathrm{mm}, b=44.5$ and $l_{\mathrm{a}} \times l_{\mathrm{r}}=120 \times 126.65 \mathrm{~mm}$. Side view is depicted in Figure 11(b). The geometry model is implemented on two substrates, each with thickness $t=1.6 \mathrm{~mm}$, conductor thickness $t_{\mathrm{c}} \approx 0.035 \mathrm{~mm}$, relative permittivity $\varepsilon_{r}=2.17$ and dissipation factor 
0.0005. The parameters of the microstrip line feed are $w=4.8 \mathrm{~mm}, d=10.8 \mathrm{~mm}, l=48.7 \mathrm{~mm}$, $l_{\mathrm{s}}=7 \mathrm{~mm}$, and $w_{\mathrm{s}}=7 \mathrm{~mm}$. With the width of the microstrip line of $4.8 \mathrm{~mm}$, the characteristic impedance is approximately $50.9 \Omega$.

The elliptical radiator will generate $\mathrm{LHCP}$ by rotating the patch by $-45^{\circ}$ around the center of the ellipse. Simulations with a finite-ground-plane model have been undertaken to optimize the size parameters using a full-wave analysis tool (IE3D Zeland software).

(a)

(b)

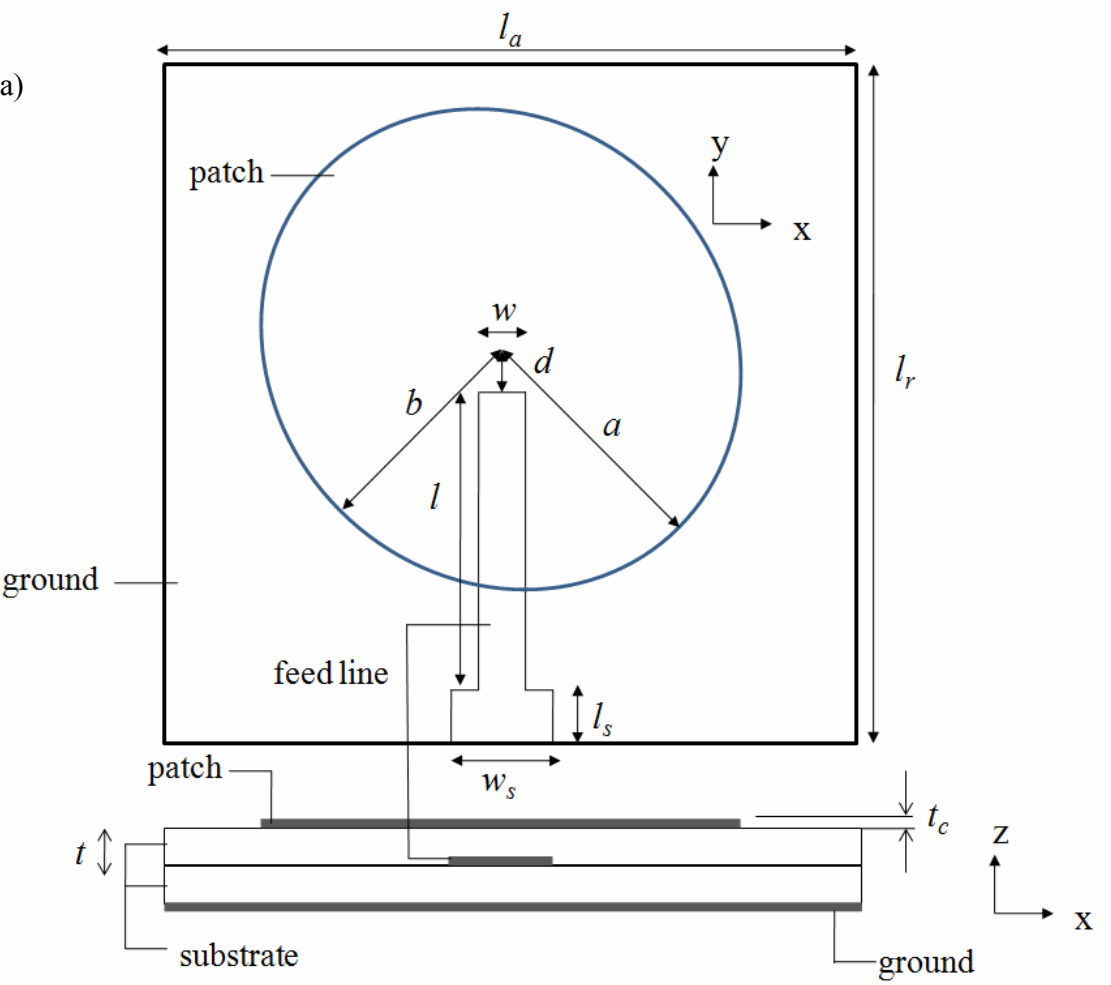

Fig. 11. Configuration of elliptical patch antenna with proximity coupled feed; (a) top view and (b) side view.

\subsubsection{Parameter study}

During the optimization process of the elliptical patch configuration, it was observed that the parameters $a$ (semi major axis) and $b$ (semi minor axis) have a strong influence on both the $\mathrm{CP}$ frequency and the AR of the antenna. Figure 12 shows the result of the simulation, in which the frequency dependence of the axial ratio is plotted for various values of the parameters $a$ and $b$ while keeping the other parameters unchanged (with the optimized values $a=45.9 \mathrm{~mm}$ and $b=44.5 \mathrm{~mm}$ ). The best circular polarization radiation is achieved for the eccentricity ranging from 19 to $28 \%$. The difference between the present result (19 to $28 \%$ ) and that in a previous work (10 to $20 \%$ ) (Shen, 1981) is presumably due to the difference in the feeding method applied to the elliptical patch. 


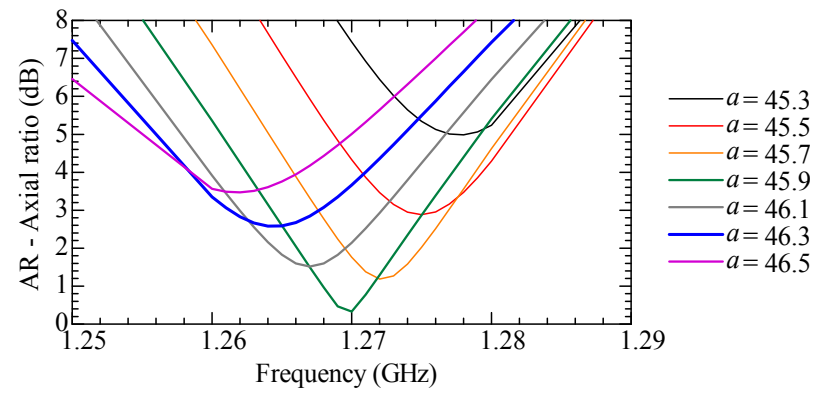

(a)

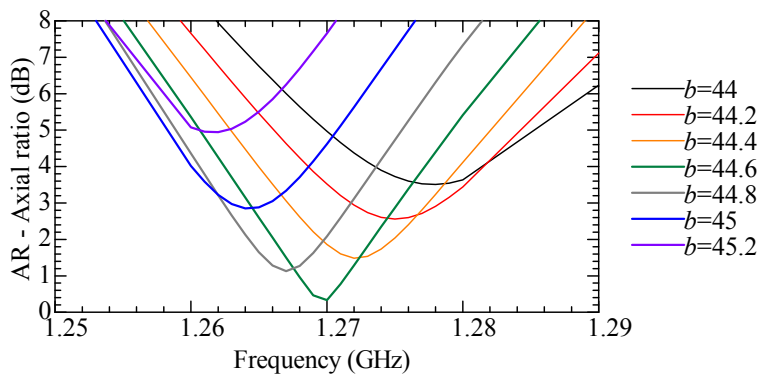

(b)

Fig. 12. Simulation results showing the frequency dependence of the axial ratio (AR) of the elliptical microstrip antenna for various values of (a) the semi-major axis $a$ and (b) semiminor axis $b$.

\subsubsection{Input and radiation characteristic}

Figure 13 shows the frequency dependence of the $S_{11}$-parameter (reflection coefficient). Although the measured parameter takes a minimum value at $1.256 \mathrm{GHz}$, somewhat smaller than the operation frequency of $f=1.27 \mathrm{GHz}$, an impedance bandwidth $\left(S_{11}<-10 \mathrm{~dB}\right)$ of more than $20 \mathrm{MHz}$ is attained around the operation frequency, in spite of the difference between the measured and simulated curves.

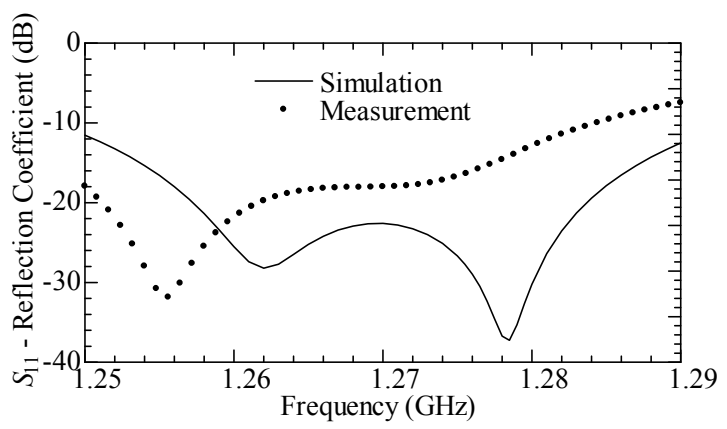

Fig. 13. Reflection coefficient vs. frequency. 


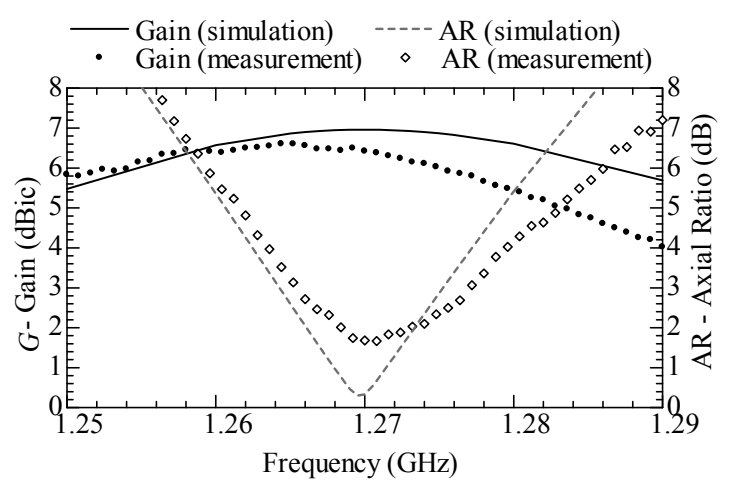

Fig. 14. Gain and AR vs. frequency at $\theta$ angle $=0^{\circ}$.

In Figure 14, the antenna gain and $\mathrm{AR}$ at $\theta=0^{\circ}$ are plotted against the frequency. From this figure, it can be seen that whereas the gain of the antenna is simulated to be $6.96 \mathrm{dBic}$ at 1.27 $\mathrm{GHz}$, the experimental result shows a smaller value by about $0.5 \mathrm{~dB}$. Such a difference between the simulation and experimental results, as also seen in other curves in Figures 15 16, can probably be ascribed to the fabrication imperfections (such as inaccuracy in the milling and etching processes, connector soldering and holes with plastic screws), the substrate loss and cable loss and also the infinite lateral extension of the substrate in the IE3D simulation while the fabricated one is a finite substrate with the same size as the ground plane. As for the frequency dependence curves of AR, a crucial parameter for circularly polarized antenna operation, Figure 14 shows that the 3-dB AR bandwidth of the simulation is $10.8 \mathrm{MHz}$ and from observation it is $10.4 \mathrm{MHz}$, ranging from 1.2658 to 1.2762 GHz. The AR bandwidth of the simulated model has satisfied the target specification (10 $\mathrm{MHz}$ ) of CP-SAR, but the range is slightly shifted from the ideal range of 1.265 to $1.275 \mathrm{GHz}$. Again, this shift is possibly caused by fabrication imperfections.

Figures 15 - 16 show the radiation pattern in terms of the gain and AR at an azimuth angle $\mathrm{Az}=0^{\circ}$ (and 180, $\mathrm{x}-\mathrm{z}$ plane) and $90^{\circ}$ (and 270, $\mathrm{y}-\mathrm{z}$ ) plane and the frequency of $f=1.27$ GHz. In Figure 15, a difference of around $0.5 \mathrm{~dB}$ is seen between the simulated and

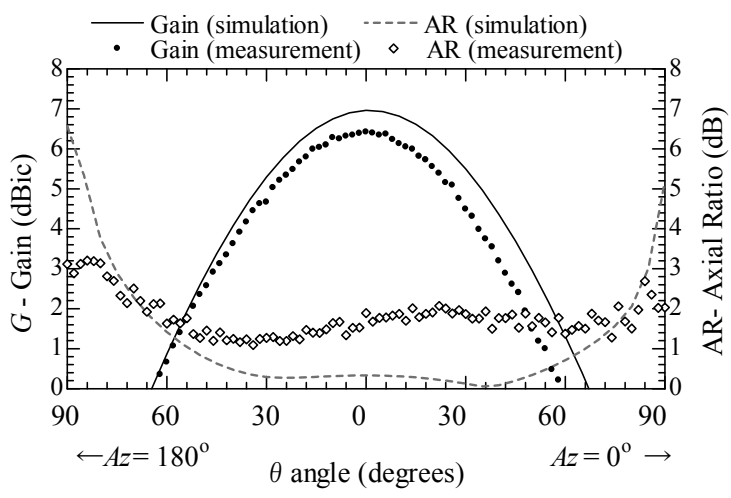

Fig. 15. Gain and AR vs. theta angle (radiation pattern) in the theta plane $\left(\mathrm{Az}=0^{\circ}\right.$ and $\left.180^{\circ}\right)$ $(\mathrm{x}-\mathrm{z}$ plane $)$ at $f=1.27 \mathrm{GHz}$. 


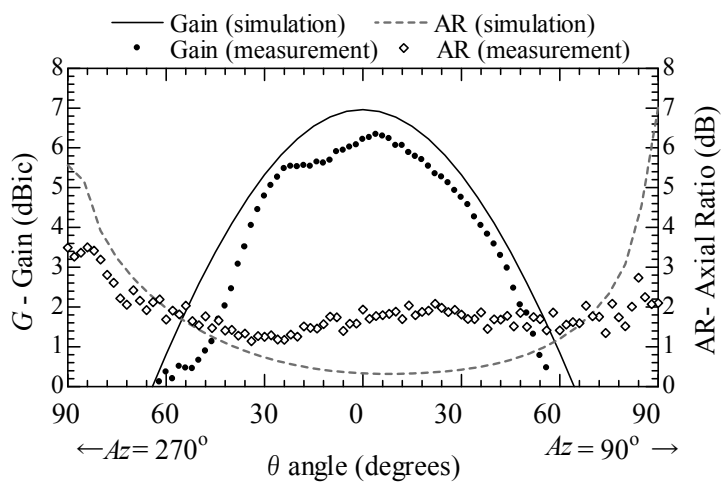

Fig. 16. Gain and AR vs. theta angle (radiation pattern) in the theta plane ( $\mathrm{Az}=90^{\circ}$ and $270^{\circ}$ ) (y-z plane) at $f=1.27 \mathrm{GHz}$.

measured results. From Figures 15 and 16, it is apparent that the measured AR performance is better in terms of AR beam width than the simulated one. This may be influenced by the imperfection effects mention above. It can also be noticed that there is a slight shift of gain pattern, and particularly the $90^{\circ}$ azimuth gain pattern has a little fluctuation. This is possibly due to the measurement system, i.e. the slight variations in antenna alignment during rotation.

\subsection{Elliptical annular ring microstrip antenna}

The patch size of the annular ring microstrip antenna is smaller than the other shapes when operated at the TM11 mode due to the longer excited patch surface current path of the TM11 mode (Chen et al., 1999), whereas in this mode the patch will behave as a resonator. One reported work on the $\mathrm{CP}$ design of the annular ring microstrip antenna is by inserting a pair of slits at the inner boundary of the annular patch, and for solving the input-impedance problem, a quarter-wavelength impedance transformer is utilized (Chen et al., 1999).

In this work on the elliptical annular ring microstrip antenna, circular polarization is produced by locating the feed point of the antenna element on the radial line rotated $45^{\circ}$ counterclockwise (or clockwise) to the semi major-axis of the ellipse for a left-handed (or right-handed) circularly polarized (LHCP/RHCP) radiation. As applied before to the elliptical microstrip antenna, we adopt the proximity-coupled feeding method.

The configuration of the radiating element together with the microstrip line feed and ground plane is shown in Figure 17(a), where important parameters are labeled. The dimensions of the radiator, and the ground plane for the elliptical patch are $a=43.7 \mathrm{~mm}, b=$ 42.5, $a_{1}=9.8 \mathrm{~mm}, b_{1}=9.3$ and $l_{\mathrm{a}} \times l_{\mathrm{r}}=120 \times 120.4 \mathrm{~mm}$. Side view is depicted in Figure 17(b). The geometry model is implemented on two substrates, each with thickness $t=1.6 \mathrm{~mm}$, conductor thickness $t_{\mathrm{c}} \approx 0.035 \mathrm{~mm}$, relative permittivity $\varepsilon_{r}=2.17$ and dissipation factor 0.0005 . The parameters of the microstrip line feed are $w=3 \mathrm{~mm}, d=13.4 \mathrm{~mm}, l=41 \mathrm{~mm}, l_{\mathrm{s}}=$ $5 \mathrm{~mm}$, and $w_{\mathrm{s}}=5 \mathrm{~mm}$. With the width of the microstrip line of $3 \mathrm{~mm}$, the characteristic impedance is approximately $68.5 \Omega$.

The elliptical radiator will generate LHCP by rotating the patch by $-45^{\circ}$ around the center of the elliptical annular ring. Simulations with a finite-ground-plane model have been 
undertaken to optimize the size parameters using a full-wave analysis tool (IE3D Zeland software) based on the method of moment (MoM) algorithm.

(a)

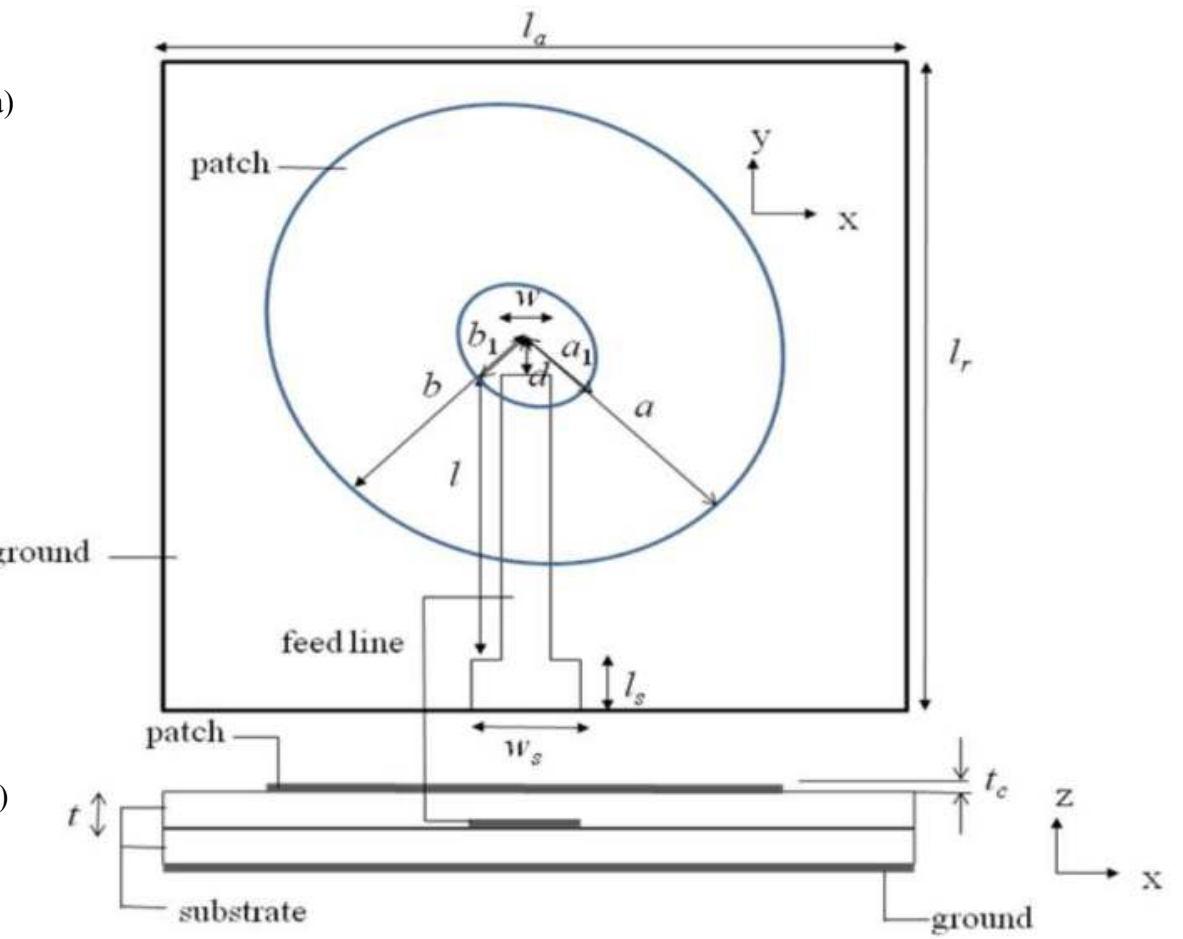

Fig. 17. Configuration of elliptical annular ring microstrip antenna with proximity coupled feed; (a) top view and (b) side view.

Figure 18 shows the frequency dependence of the $S_{11}$-parameter (reflection coefficient). Although the measured parameter takes a minimum value at $1.276 \mathrm{GHz}$, somewhat higher than the operation frequency of $f=1.27 \mathrm{GHz}$, an impedance bandwidth $\left(S_{11}<-10 \mathrm{~dB}\right)$ of more than $25 \mathrm{MHz}$ is attained around the operation frequency, in spite of the difference between the measured and simulated curves.

In Figure 19, the antenna gain and $\mathrm{AR}$ at $\theta=0^{\circ}$ are plotted against the frequency. From this figure, it can be seen that whereas the gain of the antenna is simulated to be $6.87 \mathrm{dBic}$ at 1.27 $\mathrm{GHz}$, the experimental result shows a smaller value by about $0.4 \mathrm{~dB}$. Such a difference between the simulation and experimental results, as also seen in other curves in Figures 20 21, can probably be ascribed to the fabrication imperfections (such as inaccuracy in the milling and etching processes, connector soldering and holes with plastic screws), the substrate loss and cable loss. As for the frequency dependence curves of AR, a crucial parameter for circularly polarized antenna operation, Figure 19 shows that the 3-dB AR bandwidth of the simulation is $8 \mathrm{MHz}$ and from observation it is $8.7 \mathrm{MHz}$. Even though the measurement result of 3-dB AR bandwidth is slightly better than that of the simulation result, its bandwidth is still narrower than the target specification (10 MHz). To improve this situation, the next part will consider the technique to extend the 3-dB AR bandwidth. 


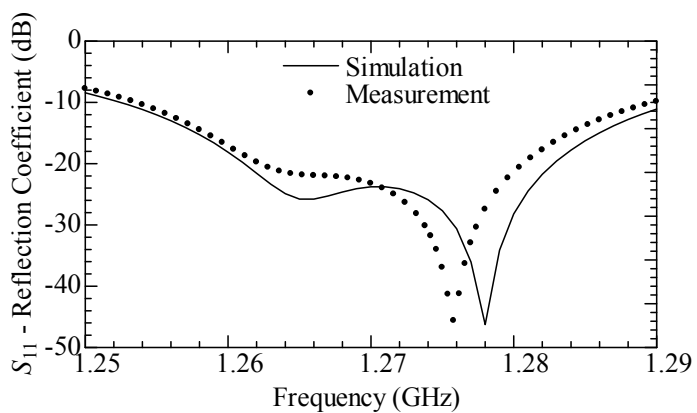

Fig. 18. Reflection coefficient vs. frequency.

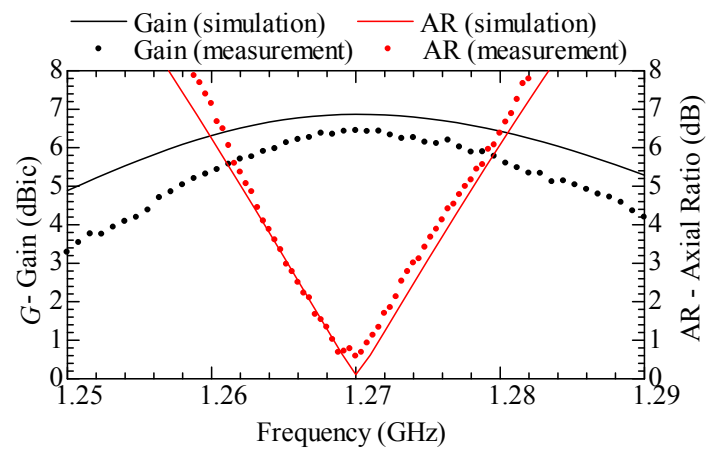

Fig. 19. Gain and AR vs. frequency at $\theta$ angle $=0$.

Figures 20 - 21 show the radiation pattern in terms of the gain and AR at an azimuth angle $\mathrm{Az}=0^{\circ}$ (and 180,$x-z$ plane) and 90 (and 270,$y-z$ ) plane and at the frequency of $f=1.27$ GHz. In Figure 20, a difference of around $0.4 \mathrm{~dB}$ is seen between the simulated and measured results. Figure 21 shows that the beam width simulated for $3-\mathrm{dB} A R$ is $155^{\circ}$ and

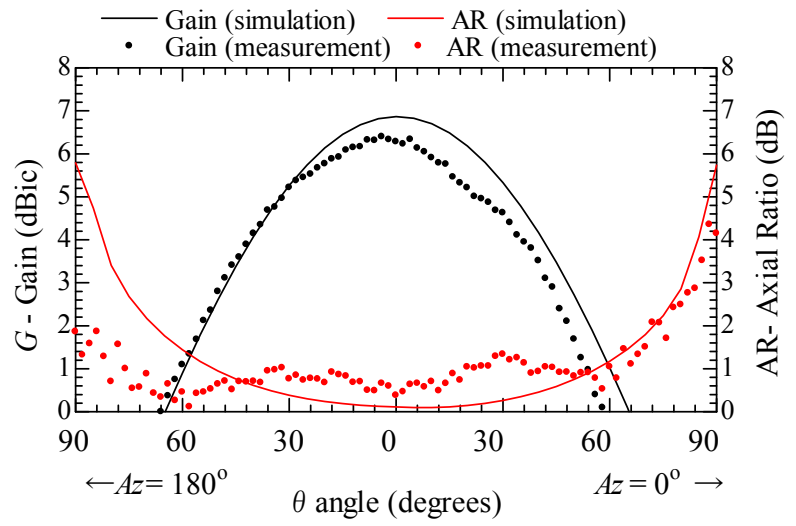

Fig. 20. Gain and AR vs. theta angle (radiation pattern) in the theta plane $\left(\mathrm{Az}=0^{\circ}\right.$ and $\left.180^{\circ}\right)$ $(x-z$ plane $)$ at $f=1.27 \mathrm{GHz}$. 


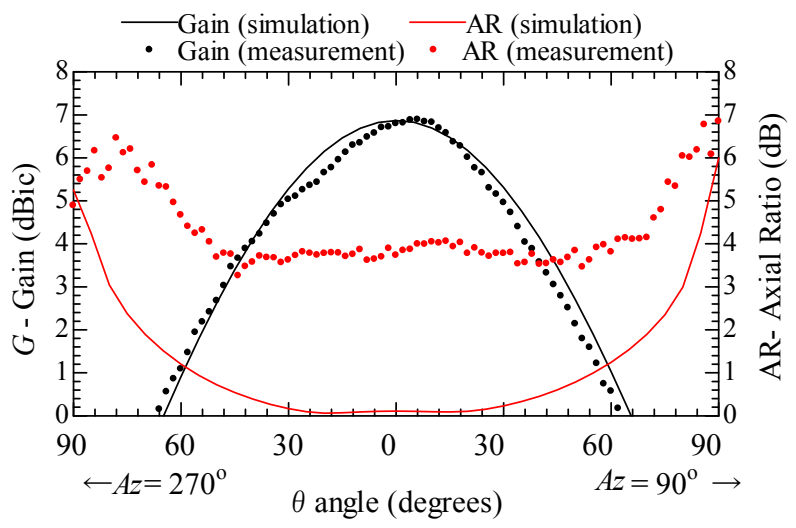

Fig. 21. Gain and AR vs. theta angle (radiation pattern) in the theta plane ( $\mathrm{Az}=90^{\circ}$ and $270^{\circ}$ ) $(y-z$ plane $)$ at $f=1.27 \mathrm{GHz}$.

on the other hand, the measurement of AR shows the value of more than $3 \mathrm{~dB}$ for all the angle range. This may be influenced by the imperfection effects mention above, most contribution presumably from fabrication imperfection. It can also be noticed that there is a slight shift and fluctuation of gain pattern. This is possibly due to the measurement system, i.e. the slight variations in antenna alignment during rotation.

\subsection{Elliptical annular ring microstrip antennas having a sine wave periphery}

In this work, we propose a single-feed, circularly polarized, annular-ring microstrip antenna operated in the L-band $(1.285 \mathrm{GHz})$. The antenna periphery is modulated with a sinusoidal wave, giving a flowery appearance. The antenna characteristics are investigated by both simulation and experiment. An annular ring microstrip antenna (ARMA) with a periodically added sector stubs at the outer and inner edge has been reported (Hong et al., 2006) to have a relatively wider bandwidth and smaller size than ordinary ARMAs. Fractal geometry applied to the periphery of microstrip antennas has also led to the reduction of the antenna size and broadening of the bandwidth (Gianvittorio et al. 2002, Krishna et al. 2009, Chen et al. 2009). Therefore, it is expected that by applying sine wave pattern to the periphery of the EARMA, broader bandwidth and reduced antenna size will be obtained. In this work the characteristics of such antennas are investigated by both simulation and experiment. It turns out that favourable characteristics of input parameter and radiation pattern in broadside direction can be achieved, ensuring its application to circularly polarized L-band applications such as global positioning system (GPS), synthetic aperture radar (SAR), television broadcasting, etc.

Circular polarization is produced from the elliptical annular-ring microstrip antenna (EARMA) by locating the feed point of the antenna element on the radial line that is rotated $45^{\circ}$ counterclockwise (clockwise) to the semi major-axis of the ellipse for a left-handed (right-handed) circularly polarized (LHCP/RHCP) radiation. We adopt the proximitycoupled feeding method that has the advantage of easier adjustment in the of design and fabrication processes, especially in producing good circular polarization with good impedance matching.

The configuration of the radiating element, together with the microstrip line feed and ground plane, is shown in Figure 22(a), where important parameters are labeled. The dimensions of 
the radiator, and the ground plane for the elliptical patch are $a=42.4 \mathrm{~mm}, b=41.1, a_{1}=9.85$ $\mathrm{mm}, b_{1}=8.9$ and $l_{\mathrm{a}} \times l_{\mathrm{r}}=130 \times 129.4 \mathrm{~mm}$. The periphery (outer ring) is an ellipse modulated with a sine wave, and in the Cartesian coordinate system, it can be expressed as

$$
\frac{x^{2}}{\left[a+m \sin 8\left(\tan ^{-1} \frac{y}{x}\right)\right]^{2}}+\frac{y^{2}}{\left[b+m \sin 8\left(\tan ^{-1} \frac{y}{x}\right)\right]^{2}}=1,
$$

where $\mathrm{m}$ is the amplitude of the sine wave, and $\mathrm{a}$ and $\mathrm{b}$ are the semi-major and -minor axis of the outer elliptical ring, respectively. The inner ellipse is given by the ordinary ellipse equation:

$$
\frac{x^{2}}{a_{1}^{2}}+\frac{y^{2}}{b_{1}^{2}}=1
$$

where $a_{1}$ and $b_{1}$ are the semi-major and -minor axis of the inner elliptical ring, respectively. In this work $m$ parameter is chosen as 3 , while the working frequency concerning the axial ratio (AR) is $1.285 \mathrm{GHz}$. Side view is depicted in Figure 22(b). The geometry model is implemented on two substrates, each with thickness $t=1.6 \mathrm{~mm}$, conductor thickness $t_{\mathrm{c}} \approx 0.035$ $\mathrm{mm}$, relative permittivity $\varepsilon_{\mathrm{r}}=2.17$ and dissipation factor 0.0005 . The parameters of the microstrip line feed are $d=15.3 \mathrm{~mm}, w=3 \mathrm{~mm}, l=43.1 \mathrm{~mm}, l_{\mathrm{s}}=6 \mathrm{~mm}$, and $w_{\mathrm{s}}=7 \mathrm{~mm}$. With the width of the microstrip line of $3 \mathrm{~mm}$, the characteristic impedance is approximately $68.3 \Omega$.

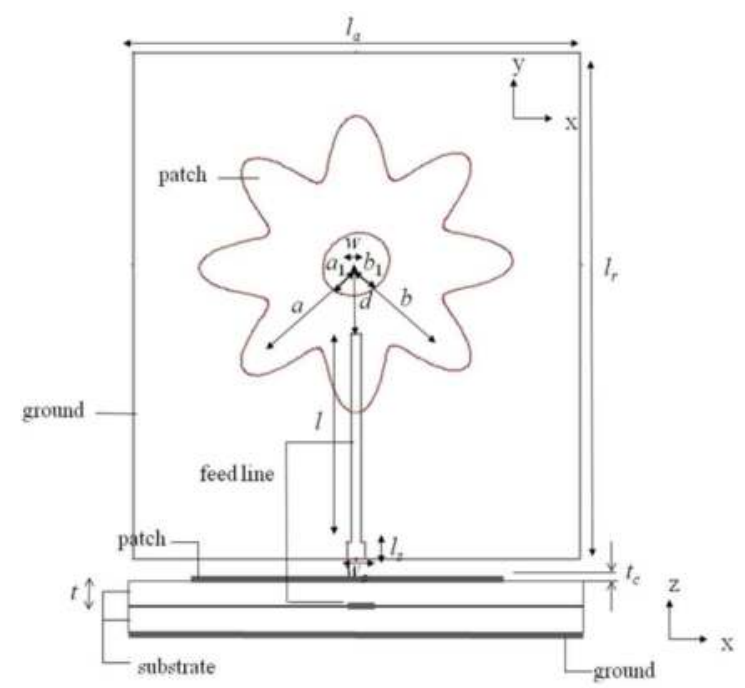

Fig. 22. Configuration of the elliptical annular ring microstrip antenna (EARMA) with proximity coupled feed; (a) top view and (b) side view.

The EARMA radiator will generate LHCP by rotating the patch by $-45^{\circ}$ around the center of the patch. Simulations with a finite-ground-plane model have been undertaken to optimize the size parameters using a full-wave analysis tool (IE3D Zeland software) based on the method of moment (MoM) algorithm. 


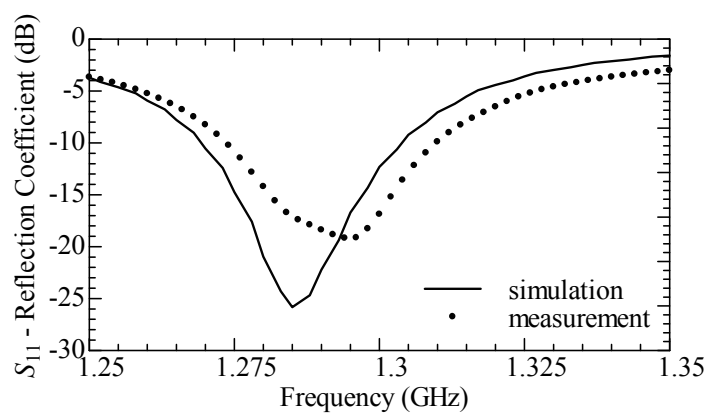

Fig. 23. Frequency dependence of simulated and measured reflection coefficient.

Figure 23 shows the frequency dependence of the $S_{11}$-parameter (reflection coefficient) obtained from the simulation and measurement. Figure 23 also shows that experimentally, the reflection coefficient takes a minimum value at $f_{1}=1.295 \mathrm{GHz}$. This frequency is somewhat higher than the operation frequency of $f_{0}=1.285 \mathrm{GHz}$, though an impedance bandwidth $\left(S_{11}<-10 \mathrm{~dB}\right)$ of more than $30 \mathrm{MHz}$ is attained around at $f_{1}$. Such a difference between the simulation and experimental results (seen also in other curves in Figures 25 and 26 shown below) can probably be ascribed to the fabrication imperfections (such as inaccuracy in the milling and etching processes, connector soldering and holes with plastic screws) and/or the substrate loss and cable loss.

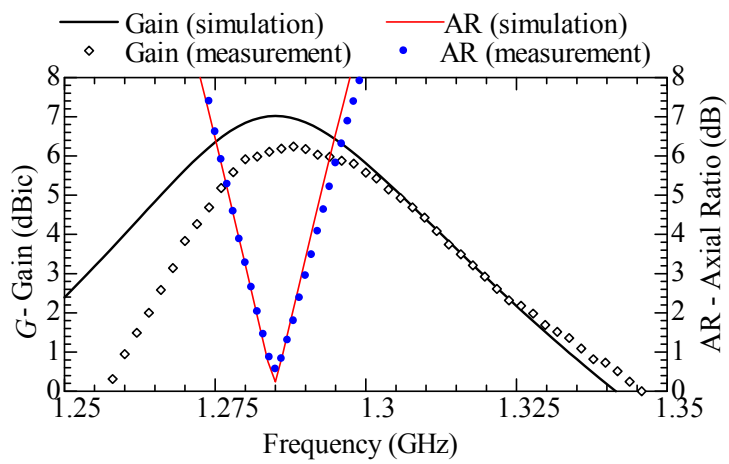

Fig. 24. Frequency dependence of simulated and measured gain and AR at $\theta$ angle $=0$.

In Figure 24, the antenna gain and $\mathrm{AR}$ at $\theta$ angle $=0 \mathrm{o}$ are plotted against the frequency. The gain of the antenna is simulated to be around $7.0 \mathrm{dBic}$ at $1.285 \mathrm{GHz}$. As for the frequency dependence curves of AR, a crucial parameter for circularly polarized antenna operation, the values of $3-\mathrm{dB}$ AR bandwidth simulated is $9.01 \mathrm{MHz}(0.70 \%)$ respectively. From the measurement, on the other hand, the gain is obtained to be $6.1 \mathrm{dBic}$, to some extent smaller than the simulated value of $7.0 \mathrm{dBic}$ at $1.285 \mathrm{GHz}$. The measured 3-dB AR bandwidth is 9.5 $\mathrm{MHz}$, slightly wider than the simulated result. This model exhibit narrower bandwidth than the ordinary EARMA model simulated at the same working frequency $(40.2 \mathrm{MHz}$ or $3.1 \%$ of $-10 \mathrm{~dB} S_{11}$ bandwidth and $9.8 \mathrm{MHz}$ or $0.76 \%$ of 3-dB AR bandwidth).

Spatial distributions (radiation pattern) of the gain and $A R$ at an azimuth angle $\mathrm{Az}=0$ o (and $180^{\circ}, x-z$ plane) and $\mathrm{Az}=90^{\circ}$ (and 270,$y-z$ plane) are shown in Figure 25 and Figure 26, 
respectively, both at the frequency of $f=1.285 \mathrm{GHz}$. At Az $=90^{\circ}$ the measured AR characteristic shows higher value than $3 \mathrm{~dB}$ at the whole $180^{\circ}$ range. This particular AR measurement result is probably contributed from the difference in geometry antenna size (between simulated and fabricated model for adjustment) due to the substrate variation. The very sensitive AR characteristic may be improved in the future by further adjustment in fabrication process.

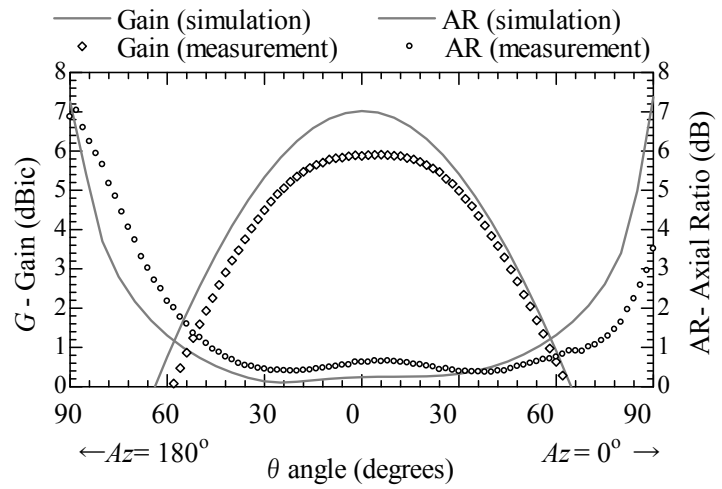

Fig. 25. Simulated and measured gain and AR vs. theta angle (radiation pattern) in the theta plane $\left(\mathrm{Az}=0^{\circ}\right.$ and $\left.180^{\circ}\right)(x-z$ plane $)$ at $f=1.285 \mathrm{GHz}$.

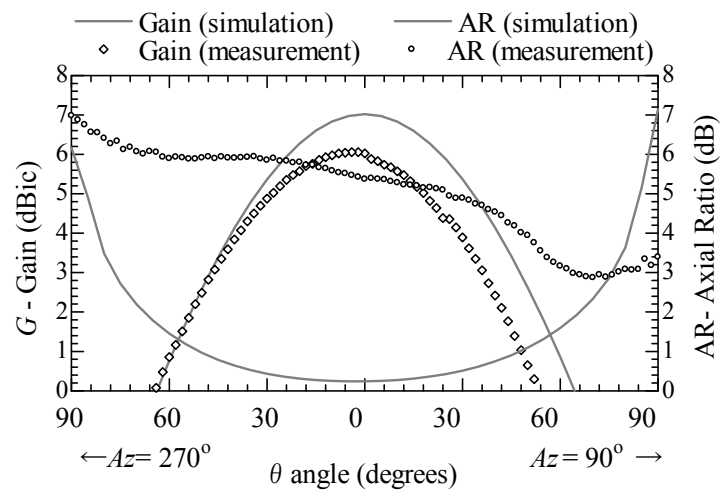

Fig. 26. Simulated and measured gain and AR vs. theta angle (radiation pattern) in the theta plane $\left(\mathrm{Az}=90^{\circ}\right.$ and $\left.270^{\circ}\right)(y-z$ plane $)$ at $f=1.285 \mathrm{GHz}$.

\section{Elliptical microstrip array antenna}

The elliptical microstrip antenna described in the part 3.2 is arranged to form a $5 \times 11$ elliptical microstrip element array and this array is simulated using Zeland IE3D on an infinite ground, with each elliptical element fed individually. The layer setting is the same as the single element elliptical microstrip antenna, this array has two layers, one is for the feed and another one is for the radiator patch. The thickness of each layer is $1.6 \mathrm{~mm}$, relative permittivity $\varepsilon_{r}=2.17$ and dissipation factor 0.0005 . Elevation spacing between elements is $125 \mathrm{~mm}$ and the azimuth spacing is $140 \mathrm{~mm}$. 
The gain obtained in the range frequency $1.25-1.29 \mathrm{GHz}$ is 16.0 to $17.6 \mathrm{dBic}$. The $3-\mathrm{dB} \mathrm{AR}$ bandwidth from this array configuration is $11.5 \mathrm{MHz}$

Figure 27 shows the antenna gain patterns $\left(\mathrm{Az}=0^{\circ}\right.$ and $\left.90^{\circ}\right)$. It is the resulting co- and crosspolarization composition patterns from RHCP elements. From this figure, the gain at $\theta=0$ o is $17.6 \mathrm{dBic}$, somewhat lower than the target gain of $20 \mathrm{dBic}$ (Table 1). However, mostly satisfactory beam patterns for CP-SAR operation are seen in both the azimuth and elevation planes. The nearest side lobe is suppressed by about $13 \mathrm{dBic}$. From Figure 28 it can be seen that in the main beam (around $\theta=0^{\circ}$ ) the $3-\mathrm{dB}$ AR beam width in the azimuth plane is $16^{\circ}$ and in the elevation plane is $38^{\circ}$.

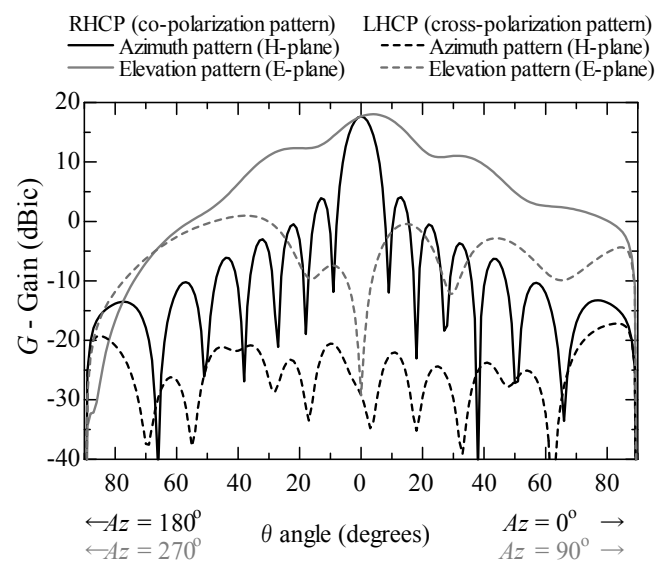

Fig. 27. Simulated radiation pattern of a $5 \times 11$ elliptical microstrip array at $f=1.27 \mathrm{GHz}$.

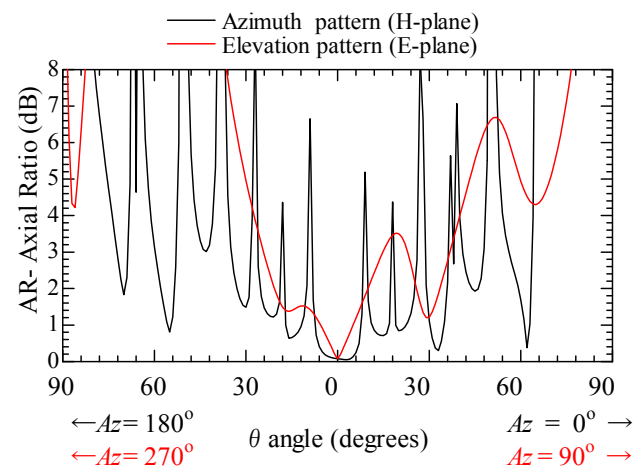

Fig. 28. Simulated AR pattern of a $5 \times 11$ elliptical microstrip array at $f=1.27 \mathrm{GHz}$.

\section{Conclusions}

In this chapter, microstrip antennas for circularly polarized synthetic aperture (CP-SAR) radar have been investigated. The CP-SAR antenna will be mounted on an Unmanned Aerial Vehicle (UAV) and operated at L-band frequency. The proposed antenna has been analyzed numerically and developed experimentally. 
The MoM analysis results of the antenna models have been presented and discussed. Best effort has been given to achieve an adequate frequency tuning range with the best performance of radiation characteristics of the antenna. Study on geometric parameters is also carried out in order to specify the one that is most influential to the axial ratio characteristic. The measurement results of the equilateral triangular microstrip antenna, elliptical microstrip antenna, elliptical annular ring microstrip antenna and the elliptical annular ring microstrip antenna having a sine wave periphery also have been presented and discussed. From these results the elliptical patch has mostly satisfied the target specification for a CP-SAR antenna element to be used onboard an UAV. The performance of an elliptical microstrip array has also been examined by simulation with good results. As for the equilateral triangular microstrip antenna and the elliptical annular ring microstrip antenna, although the AR bandwidth of these antenna are slightly smaller than the requirement for an airborne CP-SAR system, the present work has indicated that the goals can be met through a precise adjustment in the design and fabrication process in the near future. The elliptical annular ring microstrip antenna having a sine wave periphery is recommended for L-band applications including radar.

Future research will be aimed at considering the dual polarized $\mathrm{CP}$-antenna array antenna design with low cross-polarization and low mutual coupling. Low cross-polarization can be achieved by accomplish a high isolation between orthogonal input ports, lower than $-25 \mathrm{~dB}$. Another solution is to avoid uncontrolled radiation, e.g., from the feed network.

\section{Acknowledgement}

The first author would like to thank to Professor Hiroaki Kuze for his excellent guidance and support.

The authors would like to thank also to Victor Wissan, Basari, Muhammad Fauzan, Prilando Rizki Akbar, Luhur Bayuaji, Bambang Setiadi, and Ilham Alimuddin for their assistance in the antenna fabrication and measurement.

The authors also would like to thank to the Japan Society for the Promotion of Science (JSPS) for Grant-in-Aid for Scientific Research - Young Scientist (A) (No. 19686025); National Institute of Information and Communication Technology (NICT) for International Research Collaboration Research Grant 2008, Chiba University COE Start-up Program, European Space Agency (ESA) Earth Observation Category 1 (No. 6613), the research grant for Mission Research on Sustainable Humanosphere from Research Institute for Sustainable Humanosphere (RISH), Kyoto University and other research grants that have supported our research.

\section{References}

Bailey, M.C. \& Deshpande, M.D.(1985).Analysis of Elliptical and Circular Microstrip Antennas Using Moment Method. IEEE Transaction on Antennas and Propagation, 33, 954-959.

Bhattacharyya, A.K. (2008).Comparison Between Arrays of Rotating Linearly Polarized Elements and Circularly Polarized Elements. IEEE Transaction on Antennas and Propagation, 56, 2949 - 2954.

Chan, Y. K.; Chung, B. K., \& Chuah, H. T. (2004). Transmitter and Receiver Design of an Experimental Airborne Synthetic Aperture Radar Sensor. Progress In Electromagnetics Research, 49, 203-218. 
Chen, H.-M, \& Wong, K.-L. (1999). On the circular polarization operation of annular-ring microstrip antennas. IEEE Transactions on Antennas and Propagation, 47, 8, 1289-1292.

Chen, W.-L.; Wang, G. -M., \& Zhang, C.-X. (2009).Bandwidth Enhancement of a MicrostripLine-Fed Printed Wide-Slot Antenna with a Fractal-Shaped Slot. IEEE Transactions on Antenna and Propagation, 57, 7, 2176 - 2179.

Garg, R.; Bhartia, P.; Bahl, I. \& Ittipiboon, A. (2001). Microstrip Antenna Design Handbook, Artech House Inc.

Gianvittorio, J. \& Rahmat-Samii, Y. (2002).Fractal antennas: A novel antenna miniaturization technique, and applications. IEEE Antennas and Propagation Magazine, 44, 20-36.

Horn, R. (1996).The DLR airborne SAR project E-SAR.International Geoscience and Remote Sensing Symposium, 1996. IGARSS '96. 'Remote Sensing for a Sustainable Future.', Volume 3, 1624 - 1628.

Karimabadi, S. S.; Mohsenzadeh, Y.; Attari, A. R. \& Moghadasi, S. M. (2008). Bandwidth Enhancement of Single-feed Circularly Polarized Equilateral Triangular Microstrip Antenna. Progress In Electromagnetics Research Symposium, 147-150, Hangzou, China, March 24-28.

Krishna, D.D.; Gopikrishna, M.; Aanandan, C.K.; Mohanan, P. \& Vasudevan, K. (2009). Compact wideband Koch fractal printed slot antenna. IET Microwaves, Antennas and Propagation, 3, 5, $782-789$.

Levine, E.; Malamud, G.; Shtrikman, S. \& Treves, D. (1989). A Study of Microstrip Array Antennas with the Feed Network. IEEE Transactions on Antennas and Propagation, $37,4,426-434$.

Madsen, S.N.; Christensen, E.L.; Skou, N.\& Dall, J. (1991).The Danish SAR system: design and initial tests. IEEE Transactions on Geoscience and Remote Sensing, 29, 3,417 - 426.

Nemoto Y.; Nishino H.; Ono M.; Mizutamari H.; Nishikawa K. \& Tanaka K. (1991). Japanese Earth Resources Satellite-1 synthetic aperture radar.Proceedings of the IEEE , 79, 800809.

Pozar, D.M. \& Kaufman, B. (1987). Increasing the bandwidth of a microstrip antenna by proximity coupling. IEEE Electronics Letters, 23, 8, 368 - 369.

Raney, R.K.; Luscombe, A.P.; Langham, E.J. \& Ahmed S. (1991). RADARSAT. Proceedings of the IEEE , 79, pp. 839-49.

Raney, R.K. (2007). Hybrid-Polarity SAR Architecture. IEEE Transactions on Geoscience Remote Sensing, 45, 11, 3397 - 3404.

Rignot, J.M. (2000). Effect of Faraday Rotation on L-Band Interferometric and Polarimetric Synthetic-Aperture Radar Data. IEEE Transactions on Geoscience and Remote Sensing, 38, 1, 383-390.

Shen C.S. (1981). The Elliptical Microstrip Antenna with Circular Polarization. IEEE Transactions on Antennas and Propagation, 29, 1, 90-94.

Suzuki, Y.; Miyano, N. \& Chiba, T. (1987). Circularly Polarised Radiation from Singly Fed Equilateral-triangular Microstrip Antenna. Microwaves, Antennas and Propagation, IEE Proceedings $H, 134,2,194-198$.

Vetharatnam, G.; Kuan, C.B. \& Teik, C.H. (2006). Microstrip Antenna for Airbone SAR Applications. Available online at:

http://www.remotesensing.gov.my/images/default/publication_3rdmicrowave/3rdmicro wave_paper5.pdf.

Wissan, V.; Baharuddin, M.; Sri Sumantyo, J.T \& Kuze, H., (2009). Development of Measurement System for Circularly Polarized Synthetic Aperture Radar. The 16th Remote Sensing Forum - SICE, pp. 11-12, RESTEC, Tokyo, March 2009 (in Japanese).

Zeland Software Inc.(2006). IE3D User's Manual Release 11.2. 


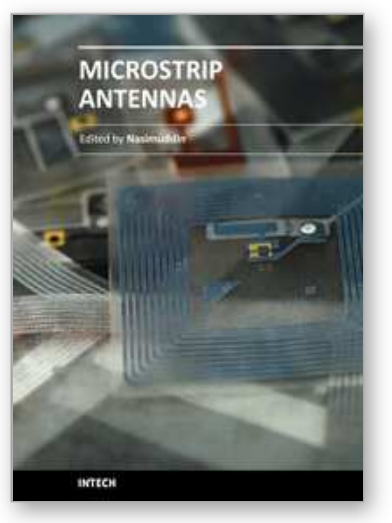

\author{
Microstrip Antennas \\ Edited by Prof. Nasimuddin Nasimuddin
}

ISBN 978-953-307-247-0

Hard cover, 540 pages

Publisher InTech

Published online 04, April, 2011

Published in print edition April, 2011

In the last 40 years, the microstrip antenna has been developed for many communication systems such as radars, sensors, wireless, satellite, broadcasting, ultra-wideband, radio frequency identifications (RFIDs), reader devices etc. The progress in modern wireless communication systems has dramatically increased the demand for microstrip antennas. In this book some recent advances in microstrip antennas are presented.

\title{
How to reference
}

In order to correctly reference this scholarly work, feel free to copy and paste the following:

Merna Baharuddin and Josaphat Tetuko Sri Sumantyo (2011). Circularly Polarized Microstrip Antennas with Proximity Coupled Feed for Circularly Polarized Synthetic Aperture Radar, Microstrip Antennas, Prof. Nasimuddin Nasimuddin (Ed.), ISBN: 978-953-307-247-0, InTech, Available from: http://www.intechopen.com/books/microstrip-antennas/circularly-polarized-microstrip-antennas-with-proximitycoupled-feed-for-circularly-polarized-synthe

\section{INTECH}

open science | open minds

\author{
InTech Europe \\ University Campus STeP Ri \\ Slavka Krautzeka 83/A \\ 51000 Rijeka, Croatia \\ Phone: +385 (51) 770447 \\ Fax: +385 (51) 686166 \\ www.intechopen.com
}

\author{
InTech China \\ Unit 405, Office Block, Hotel Equatorial Shanghai \\ No.65, Yan An Road (West), Shanghai, 200040, China \\ 中国上海市延安西路65号上海国际贵都大饭店办公楼 405 单元 \\ Phone: +86-21-62489820 \\ Fax: $+86-21-62489821$
}


(C) 2011 The Author(s). Licensee IntechOpen. This chapter is distributed under the terms of the Creative Commons Attribution-NonCommercialShareAlike-3.0 License, which permits use, distribution and reproduction for non-commercial purposes, provided the original is properly cited and derivative works building on this content are distributed under the same license. 